\title{
The Relationship between Chew and Cross Bite: Review
}

ISSN: 2637-7764

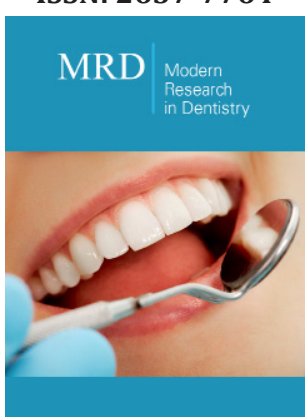

*Corresponding author: PEREIRA Karine Barbosa, School of Dentistry, Rio de Janeiro State University (UERJ), Rio de Janeiro, Brazil

Submission: 僵 May 17, 2021

Published: 毕 May 24, 2021

Volume 6 - Issue 3

How to cite this article: PEREIRA Karine Barbosa. The Relationship between Chew and Cross Bite: Review. Mod Res Dent. 6(3). MRD. 000638. 2021.

DOI: 10.31031/MRD.2021.06.000638

Copyright@ PEREIRA Karine Barbosa, This article is distributed under the terms of the Creative Commons Attribution 4.0 International License, which permits unrestricted use and redistribution provided that the original author and source are credited.

\section{PEREIRA Karine Barbosa*}

School of Dentistry, Rio de Janeiro State University (UERJ), Rio de Janeiro, Brazil

\section{Opinion}

Occlusion can be defined as the set of functional and dynamic relationships between the occlusal surfaces of the teeth and all structures of the stomatognathic system. To define malocclusion, Teixeira et al. [1], report that it is the morpho functional deviation of the masticatory apparatus during dental occlusion.

Rocabado et al. [2], defines the stomatognathic system as a body unit formed by maxilla, mandible, dental arches, salivary glands, nerves, vessels, temporomandibular joint (TMJ) and muscles.

Crossbite is an alteration characterized by the inability of the two arches to occlude normally in the lateral and/or anteroposterior relationship, which can be caused by localized problems of tooth position, alveolar growth or due to bone discrepancy between the maxilla and mandible [3].

According to Vadiakas et al. [4], crossbite is a malocclusion frequently diagnosed in children with mixed dentition and can be defined as an alteration resulting from inadequate positioning of maxillary teeth in relation to mandibular teeth, visualized during occlusion, which can be present both in the anterior and posterior regions.

The influence of unilateral crossbite on the development of facial asymmetry has been reported. Crossbites are very frequent malocclusions, causing profile alterations when not treated early, since they are not self-corrected with the eruption of permanent teeth [5].

In a study performed by Martins et al. [6], they approached a prevalence of anterior crossbite around $7.6 \%$ of the children, also affecting about $1 \%$ of the children between 2 and 6 years of age. The anterior crossbite etiology has multifactorial links and may belong to the class of hereditary anomalies resulting from maxillomandibular discrepancy.

The bilateral alternating mastication is the physiological and ideal mastication for the human being, with masticatory cycles on both sides, and with the presence of rotatory jaw movements. It is performed with the lips occluded and considered the chewing pattern (Cattoni 2004).

There is a premature contact during centric occlusion, leading the child to adopt a deviated mandibular posture by adaptation. This specific type of crossbite is characterized by a functional mandibular protrusion, caused by an interference in the trajectory of mandibular closure. When this protruded mandibular posture is not corrected early, it can cause longterm deviations in facial growth and development, which can result in facial asymmetry, and can be corrected with orthognathic surgery.

Crossbite is an occlusal alteration that is also present in the deciduous dentition. Thus, it is of utmost importance that the professional knows the profile of these patients and the prevalence of crossbite, in order to intervene in time to prevent dysfunctions of greater proportions. 
It is extremely important that the crossbite treatment must be done early in order to prevent it from evolving to skeletal, aiming the development of normal occlusion, esthetic and functional. It can be treated as a minimum age around four years old. The type of appliance to be indicated depends on the age of these patients and the complexity of the case.

\section{References}

1. Teixeira MJ, Yeng LT, Kazyiama HHS (2007) Physiopathology of musculoskeletal pain. In: Eixeira MJ, Yeng LT, Kazyiama HHS (Eds.), colaboradores. Síndrome dolorosa miofacial e dor musculoesquelética, São Paulo: Roca, Brazil, pp: 53-70.
2. Robocado SM, Tapia V (1987) Radiographic study of craniocervical relation in patients under orthopedic treatment and the incidence of related symptom. The Journal of Craniomandibular \& Sleep Practice 5(1):36-42.

3. Janson (2004) Treatment of the total crossbite: two-phase approach clin ortodon dental press. Maringá, Brazil, 3(5).

4. Vadiacaz GP, Roberts MW (1992) Primary posterior crossbite: diagnostic and treatment. J Clin Pediatr Dent 16(1): 1-4.

5. Kutin G, Hawes RR (1969) Posterior cross-bites in the deciduous and mixed dentitions. Am J Orthod 56(5): 491-504.

6. Martins DR, Almeida ZR, Dainesi EA (1994) Anterior and posterior crossbites. Odonto Master, Orthodontics 1(2): 1-19. 